\title{
ANALYTICAL MODELING OF DSG IN PARABOLIC TROUGH SOLAR COLLECTORS
}

\author{
C. Oliveira, N. Fraidenraich, O. Vilela, A. Cunha \\ Federal University of Pernambuco - UFPE, Departamento de Energia Nuclear, Av. Prof. Luiz Freire, 1000, 50740-540, \\ Recife (PE), Brazil, Phone/Fax: (+55) 81 2126-8252 / 2126-8250 e-mail: caaoliveira@gmail.com
}

\begin{abstract}
Direct steam generation (DSG) in the absorber pipes of parabolic trough solar collectors is a promising procedure since the thermal fluid is water instead of thermal oil, as conventional solar concentrating systems use. It enables higher cycle temperatures and efficiencies, reducing the cost of the system. This paper presents an analytical model of (DSG) process in parabolic trough collectors. A collector row was divided in three sections and for each section a system of differential equations was derived. The model was implemented and simulations performed using a configuration and parameters similar to works published in the technical literature. Results of simulation have shown good agreement with them and allow obtaining many important parameters of the (DSG) process along the collector row: external and internal absorber temperature, fluid flow and temperature, vapor title and useful energy. A linear relationship between useful energy and collected irradiance has been obtained. Using the utilizability method, this result enables to make long term predictions about the system's performance.
\end{abstract}

Keywords: DSG, Modeling, Parabolic Trough, Solar Energy.

\section{INTRODUCTION}

Parabolic trough solar concentrators coupled to steam turbine power converters are nowadays the most proven and reliable solar thermal technology for electricity production. The largest solar energy generating facility with that technology was built in the Mojave Desert by Luz Industries. Named Solar Electricity Generating Systems-SEGS, the first power station started operation in 1984 and the last in 1991, totalizing 354 MWe. United States and Spain have together an accumulated power above 1,218 MWe operating today. Spain has others 1,250 MWe under construction (Fernández-García et al., 2010) (Protermosolar, 2011).

The present generation of thermal power plants with line focus collectors uses oil as thermal fluid to transfer (HTF) the energy delivered by the solar field to an oil/water heat exchanger. The water steam coming out of the heat exchanger runs a Rankine cycle. The physical stability of the thermal fluid requires not overpassing a specified temperature limit, usually around $400{ }^{\circ} \mathrm{C}$, as a guarantee of suitable working conditions. At the same time that temperature limit establishes the maximum cycle efficiency that the system can reach.

Direct steam generation (DSG) in the absorber pipes of parabolic trough collectors is a promising alternative to the use of thermal oil in the absorber of parabolic collectors since it enables higher cycle temperatures and, consequently, higher efficiencies to be reached, reducing at the same time the cost of investment of the power system (Zarza et al., 2004).

Once proven the technical feasibility of the DSG solar technology (Zarza et al., 2004), a first commercial power plant was designed within the terms of the INDITEP project (Zarza et al., 2006). Afterwards, two projects to develop pre-commercial demonstration plants based on DSG technology were announced (Zarza et al., 2008) (Eck et al., 2008), both of them to be implemented in Spain.

In this work, it is proposed a simple model of collector's behavior belonging to DSG systems. In terms of configuration, size and physical properties of the absorber region, it is followed the main lines of reference (Zarza et al., 2008) that had its name and location recently changed (Fernández-García et al., 2010). Established on physical grounds, the model to be described enables a clear understanding of the dependence of the collector's performance on key design and operating parameters.

\section{ANTECEDENTS AND SPECIFIC ASPECTS OF THE DSG TECHNOLOGY}

In a previous paper, solutions for temperature and power delivery profiles in concentrating linear collectors were derived for a homogeneous thermal fluid (Fraidenraich et al., 1997). The heat losses considered were a second degree polynomial of the difference between absorber and environment temperature. In this paper, a system of differential equations for DSG collectors is derived. Some important differences exist between the model in this paper and Fraidenraich et al. (1997): a) Water vapor is generated in the absorber of the solar collector instead of using an intermediate thermal fluid like in SEGS; b) Heat losses can be represented by a general function of the difference between absorber and environment temperature, as long as it is derivable with respect to the absorber temperature and c) The heat transfer coefficient between absorber wall and thermal fluid for homogeneous fluid flow and two phases fluid (water-vapor) is considered as variable along the absorber and dependent on the fluid temperature. 
Two aspects of this technology deserve special consideration. The first one refers to the fact that the thermal fluid, water, cools down to ambient temperature. In the (HTF) cycle the thermal fluid, after delivering its available thermal energy, cools down no more than up to $200^{\circ} \mathrm{C}$, approximately, which becomes then the input temperature in the solar field collectors'. In the DSG technology the thermal fluid cools to ambient temperature requiring, therefore, either external energy to preheat the fluid up to evaporation temperature or a regenerative cycle to avoid energy exchange with external heat sources in the preheating region. The second aspect has to do with flow stability and heat transfer from the absorber walls to the thermal fluid. It has been experimented and concluded during the DISS project (Zarza et al., 2004) that the recirculation concept proved to be controllable and stable under solar transients, having this mode been chosen for the pre-commercial DSG power plants (Zarza et al., 2008) (Eck et al., 2008).

Some specific aspects of DSG solar collectors are next described. Then the equations of the model are set up and the method of solution presented.

\section{FIELD DESCRIPTION}

A DSG solar power plant is integrated by two subsystems, the solar vapor field and the Rankine cycle power block. A detail of a column of solar collectors where preheating, evaporation and superheating is implemented is shown in Fig. 1. Every row has ten parabolic trough collectors connected in series. The first three collectors are used for water preheating, while in the next five the preheated water is evaporated. The last two collectors in every row constitute the steam superheating section.

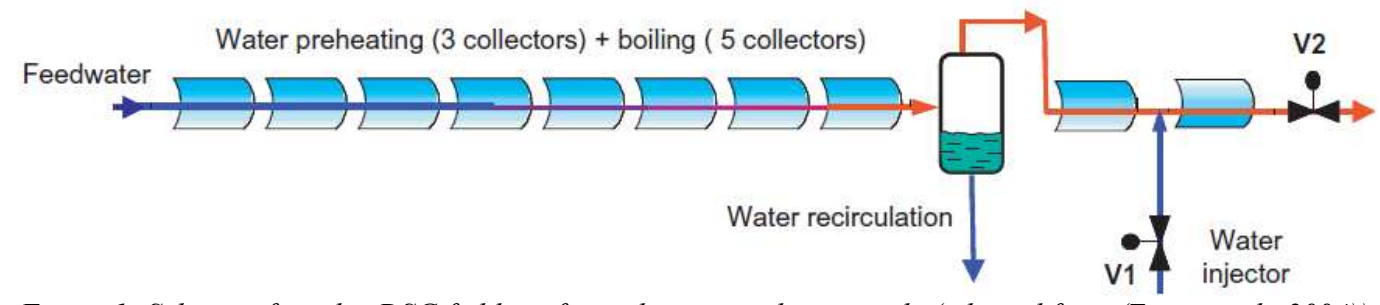

Figure 1: Scheme of a solar DSG field configured in recirculation mode (adapted from (Zarza et al., 2004)).

The end of the evaporation section are connected to the inlet of the superheating steam section by a water/steam separator A small fraction of the input mass flow is not evaporated and is returned to the collector input. In this way the evaporating section is never dry, always remaining a small and pre-established quantity of liquid water. A water injector placed at the inlet of the last collector controls the temperature of the superheated steam produced by the row of collectors.

\section{MODEL EQUATIONS}

The analysis that follows considers the collector row divided in three sections, preheating, phase change (evaporation) and superheating. Preheating and superheating deal with homogeneous phase flow and the treatment, unless minor changes, is similar to the one by Fraidenraich et al. (1997).

In (Fraidenraich et al., 1997), it was derived a relationship between useful energy $\left(q_{u}\right)$ and length of the absorber $(x)$, regarding the heat losses a second degree polynomial of the difference between absorber and ambient temperature. It is meaningful to use a similar approach in the present case introducing, nevertheless, the following physical modifications: A) Homogeneous flow: 1) The heat transfer coefficient between absorber and fluid $(h)$, depends on fluid temperature $\left(T_{f}\right)$, varying then along the absorber $(x)$. In (Fraidenraich et al., 1997), $(h)$ was considered uniform along the absorber 2) Heat losses are considered a general function of the difference between absorber and environment temperatures $\left(T_{a}-T_{e n v}\right)$. As mentioned, in (Fraidenraich et al., 1997) heat losses were considered a second degree polynomial of $\left(T_{a}-T_{\text {env }}\right)$. However, polynomials of higher order degree not always accept analytical solutions or, if they exist, are somewhat cumbersome to be obtained. B) Phase change flow: Apart from the main physical modification for an absorber with direct generation of vapor, considerations made for the case (A) are also valid in this case; C) Because of the high pressures to which the absorber tube is subject its walls are thick and significant temperature differences are verified between the external and internal wall. The preheating, phase change and superheating sections extend from $x=0$ to $L_{1} ; x=L_{1}$ to $L_{2}$ and $x=L_{2}$ to $L_{3}$, respectively.

\section{Equations for homogeneous fluid flow}

It was considered, at first, the equations for the useful energy density $\left(\mathrm{q}_{\mathrm{u}}\right)$ for a homogeneous fluid flow

$$
\begin{aligned}
& q_{u}=h\left(T_{a, \text { int }}-T_{f}\right) \\
& q_{u}=\frac{\dot{m} C_{p}}{P} \frac{d T_{f}}{d x} \\
& q_{u}=q_{a}-q_{l}
\end{aligned}
$$

where $T_{a, \text { int }}$ is the absorber temperature measured at the internal radius; $\dot{\mathrm{m}}$, fluid mass flow; $C_{p}$, fluid specific heat; $P$, absorber perimeter at internal radius. The energy conservation equation (Eq. 3), relates absorbed irradiance $\left(q_{a}\right)$, heat losses $\left(q_{l}\right)$ and useful energy $\left(q_{u}\right)$. All the density energy variables $(q)$ are expressed in terms of the internal radius of the absorber $\left(\mathrm{W} / \mathrm{m}^{2}\right)$. 
It should be noticed that the heat loss $\left(q_{l}\right)$ is a function of the external absorber temperature $\left(T_{a, e x t}\right)$ and the main physical processes occur at the interface between absorber and fluid flow, it means at the internal absorber radius $\left(T_{a, i n t}\right)$. It will be necessary, therefore, to find a relationship between both absorber temperatures.

If the function representing the heat losses is derivable, the heat loss coefficient $(U)$ can be conveniently defined as Fraidenraich et al., (1997)

$$
U\left(T_{a, e x t}\right)=\frac{d q_{l}}{d T_{a, e x t}}
$$

and derivation of Eq. (3), results in

$$
\frac{d q_{u}}{d x}=-U\left(T_{a, e x t}\right) \frac{d T_{a, e x t}}{d x}
$$

In differential form, Eq. (1) can be written as

$$
\frac{d q_{u}}{d x}=h\left(\frac{d\left(T_{a, \text { int }}\right)}{d x}-\frac{d T_{f}}{d x}\right)+\left(T_{a, \text { int }}-T_{f}\right)\left(\frac{d h}{d T_{f}} \frac{d T_{f}}{d x}\right)
$$

and introducing Eq. (2), it can be obtained

$$
\frac{d q_{u}}{d x}=h\left(\frac{d T_{a, \text { int }}}{d x}\right)-h \frac{P}{\dot{m} C_{p}} q_{u}+\frac{P}{\dot{m} C_{p}} \frac{1}{h} \frac{d h}{d T_{f}} q_{u}^{2}
$$

Derivative of internal absorber temperature and system solution

To obtain the derivative $\left(d T_{a, \text { int }} / d x\right)$, we calculate the relationship between internal and external temperatures of the absorber. Heat conduction between both faces of the absorber is given by

$$
q_{u}=\frac{k}{r_{\text {int }} \ln \left(\frac{r_{\text {ext }}}{r_{\text {int }}}\right)}\left(T_{a, e x t}-T_{a, \text { int }}\right)
$$

or

$$
q_{u}=\Gamma\left(T_{a, \text { ext }}-T_{a, \text { int }}\right)
$$

where

$$
\Gamma=\frac{k}{r_{\text {int }} \ln \left(\frac{r_{\text {ext }}}{r_{\text {int }}}\right)}
$$

Derivation of Eq. (9) combined with (5) leads to

$$
\frac{d T_{a, \text { int }}}{d x}=-\frac{1}{\Gamma}\left(1+\frac{\Gamma}{U}\right) \frac{d q_{u}}{d x}
$$

Introduced then, in Eq. (7), results equal to

$$
\frac{d q_{u}}{d x}=-\frac{P}{\dot{m} C_{p}} \frac{q_{u}}{1+\frac{h}{\Gamma}\left(1+\frac{\Gamma}{U}\right)}\left[h-\frac{1}{h} \frac{d h}{d T_{f}} q_{u}\right]
$$

The coefficient $(h)$ depends on $\left(T_{f}\right)$ and coefficient $(U)$ depends on $\left(T_{a, \text { ext }}\right)$.Thus, differential equation (12), associated with ancillary Eqs. (2) and (5), is the solution of the problem. The solution obtained depends, essentially, on three heat transfer coefficients $(h),(U)$ and $(I)$, that express the interaction absorber-fluid, absorber-environment and heat conduction from external to internal absorber wall. 
If heat losses $\left(q_{l}\right)$ are represented by a second degree polynomial and the heat transfer coefficient $(h)$ does not depend on $\left(T_{f}\right)$, it can be verified that Eq. (12) reproduces the analytical solution for the useful energy found in (Fraidenraich et al., 1997). A lower order approximation can still be derived from Eq. (12) if coefficients $(h)$ and $(U)$ are considered constant.

\section{Steam generation region}

Consider the following expression for the instantaneous useful energy

$$
q_{u}(x)=h(\chi)\left(T_{a, \text { int }}(x)-T_{e v}\right)
$$

where $h(\chi)$ is the heat transfer coefficient between the internal absorber surface under phase change conditions; $(\chi)$ is the vapor title, varying along the distance $(x) ;\left(T_{a, \text { int }}\right)$ absorber temperature of the receiver at the internal radius $\left(r_{i}\right) ;\left(T_{e v}\right)$ the evaporation temperature of the biphasic fluid, uniform along this region. The evaporation temperature is a parameter which can be selected to optimize the thermodynamic cycle. The fluid enthalpy is given by

$$
h_{f}=h_{l}(1-\chi)+h_{v} \chi
$$

Where $h_{l}$ is the enthalpy of saturated liquid and $h_{v}$ is the enthalpy of the saturated steam. The useful energy $\left(q_{u}\right)$, expressed as a function of the vapor title $(\chi)$ can then be written as

$$
q_{u}(x)=\frac{\dot{m} h_{e v}}{P} \frac{d(\chi)}{d x}
$$

Eq.(15) can be obtained as a balance between the change in enthalpy of the mixture of water-vapor and the energy conversion of solar radiation into useful energy.

As in the case of homogeneous fluid, Eq.(13) can be expressed in differential form

$$
\frac{d q_{u}}{d x}=\frac{d h(\chi)}{d \chi} \frac{d \chi}{d x}\left(T_{a, \text { int }}-T_{e v}\right)+h(\chi) \frac{d T_{a, \text { int }}}{d x}
$$

and substituting $\left(T_{a, \text { int }}-T_{e v}\right)$ from Eq.(13) and $(d \chi / d x)$ from Eq.(15), a differential equation for $\left(q_{u}\right)$ is obtained

$$
\frac{d q_{u}}{d x}=\frac{W}{\dot{m} h_{e v}}\left(\frac{1}{h(\chi)} \frac{d h(\chi)}{d \chi}\right)\left(q_{u}(x)\right)^{2}+h(\chi) \frac{d T_{a, \text { int }}}{d x}
$$

where $h(\chi)$ is obtained from experimental measurements for the specific conditions of geometry and physics of the collector absorber.

The derivative of the internal absorber temperature $\left(T_{a, i n t}\right)$ has been obtained in the previous section (Eq.(11)) and is also valid in this case, since it deals with heat losses to the environment and heat conduction from external to internal radius. Introducing Eq.(11) in Eq.(17), the differential equation for useful energy $\left(q_{u}\right)$ can be written as

$$
\frac{d q_{u}}{d x}=\frac{P}{\dot{m} h_{e v}} \frac{1}{\left[1+\frac{h(\chi)}{\Gamma}\left(1+\frac{\Gamma}{U}\right)\right]}\left(\frac{1}{h(\chi)} \frac{d h(\chi)}{d \chi}\right)\left(q_{u}(x)\right)^{2}
$$

Similarly, as in the case of homogeneous fluid flow, Eq.(18) has to be solved together with Eqs. (5) and (15).

The system formed by Eqs. (5), (15) and (18) also depends on heat transfer coefficients $(U)$ and $(I)$, as in previous section. The main modification on the physics of the problem stems from the introduction of the heat transfer coefficient $(h(\chi))$ and Eq.(15), which calculates the rate of change of vapor title $(\chi)$.

\section{Input conditions}

First section $\left(x=0-L_{1}\right)$

Usually the input temperature $T_{f, i n}=T_{f}(0)$ is given as an initial condition. Regarding the absorber temperature, at first it was calculated a general expression for both absorber temperatures, which can then be specified for input conditions. Combining Eq. (1) and (9) it is derived 


$$
q_{u}\left(\frac{1}{h}+\frac{1}{\Gamma}\right)=T_{a, e x t}-T_{f}
$$

and introducing Eq.(3), an expression to calculate $\left(T_{a, e x t}\right)$ as a function of $\left(T_{f}\right)$ is obtained

$$
T_{a, \text { ext }}+q_{l}\left(T_{a, \text { ext }}\right)\left(\frac{1}{h\left(T_{f}\right)}+\frac{1}{\Gamma}\right)=T_{f}+q_{a}\left(\frac{1}{h\left(T_{f}\right)}+\frac{1}{\Gamma}\right)
$$

Eq.(18) gives $\left(T_{a, e x t}\right)$ at any position along the absorber. In particular, it will be used to calculate $\left(T_{a, e x t}\right)$ at the absorber input. This equation is valid for any well behaved function $\left(q_{l}\right)$ of the external absorber temperature that enables to calculate $\left(T_{a, e x t}\right)$, at least by a numerical procedure. The internal absorber temperature can now be obtained as function of $T_{a, \text { ext }}$ combining Eqs.(1) and (9)

$$
T_{a, \text { int }}=\frac{1}{1+\frac{\Gamma}{h}}\left(\frac{\Gamma}{h} T_{a, e x t}+T_{f}\right)
$$

Assuming that $\left(T_{f}\right)$ is known at $\mathrm{x}=0$, Eqs. (18) and (19) yield $\left(T_{a, \text { int }}(0)\right)$ and $\left(T_{a, e x t}(0)\right)$. Consequently the useful energy $\left(q_{u}(0)\right)$ can be calculated using Eq.(1). The system of Eqs. (12), (2) and (5) can then be integrated to obtain $\left(q_{u}\right),\left(T_{f}\right)$ and $\left(T_{a, e x t}\right)$ along the preheating section. The fluid output temperature of this section $\left(T_{f}\left(L_{l}\right)\right)$ is the evaporation temperature $\left(T_{e v}\right)$, parameter that can be selected to optimize the thermodynamic cycle.

Second section $\left(x=L_{1}-L_{2}\right)$

The initial conditions at the second section are the output of the first section. It is necessary to add that the input vapor title is zero $\left(\chi\left(L_{1}\right)=0\right)$ and the output vapor title is a pre-established value $\left(\chi\left(L_{2}\right)=75 \%\right.$, e.g. $)$.

Third section $\left(x=L_{2}-L_{3}\right)$

The initial conditions are already calculated at the output of the second section. The output conditions are also preestablished. The pressure corresponds to the equilibrium pressure at evaporation temperature and the maximum superheating temperature is a design parameter, very important to determine the thermodynamic cycle efficiency.

\section{MODEL SOLUTION}

The Mathcad software was used to solve the systems of equations. The systems of differential equations are solved using the fourth-order Runge-Kutta method. Parameters used in simulation are as much as possible the same of (Zarza et al. 2006) in order to compare the results. The Dittus-Boelter correlation (1930) was used to predict the heat transfer coefficient for homogeneous flows, while the Goebel correlation (Goebel, 1999) was used for two-phase flow section. In this initial implementation, pressure drops, losses due to piping, tracking errors, dirt on mirrors or envelop, and others minor losses are not considered. However, losses from row shading were taken into account.

The code developed was used to simulate the behavior of a $980 \mathrm{~m}$ row of collectors, operating in recirculation mode, using one hour intervals and the irradiance data of (Zarza et al. 2006) for the city of Almería - Spain. The program allows obtaining many of the variables involved in DSG process, actually, all those present in the modeling equations. Results achieved for superheated steam mass flow and thermal output power for a winter day (Jan $\left.29^{\text {th }}\right)$ and a summer day (Jun $\left.12^{\text {th }}\right)$ are shown in Fig. 2.

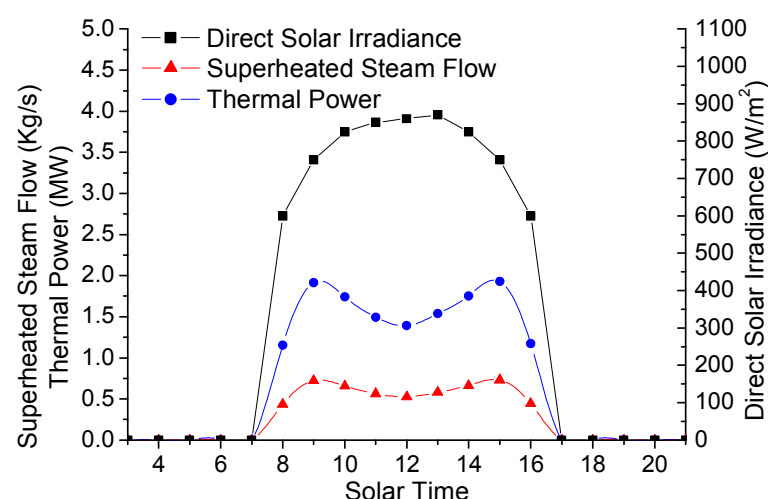

(a)

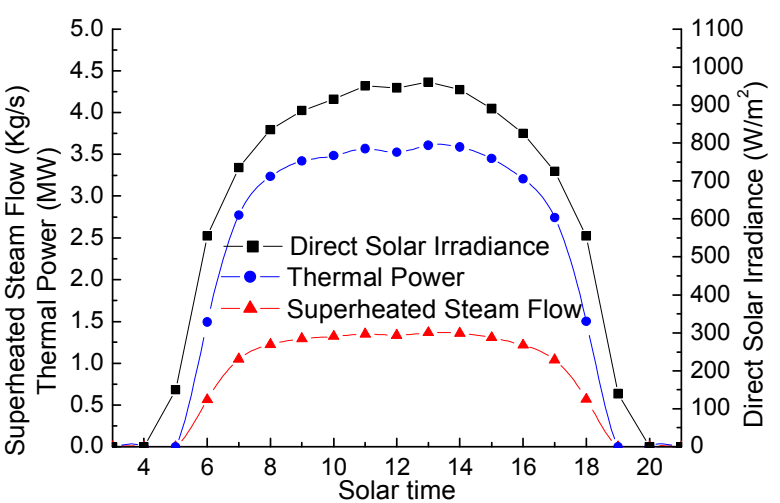

(b)

Figure 2 - Simulation results for a $980 \mathrm{~m}$ row of collectors for (a) January $29^{\text {th }}$ and (b) June $12^{\text {th }}$. 
Although some parameters used in the simulation are not the same as those used in (Zarza et al. 2006), results shown in Fig. 2 present good agreement with results of INDITEP project (for one row of collectors). It is possible to observe a decrease in thermal power at noon for January $29^{\text {th }}$ due to angle of incidence of the direct solar radiation.

The fluid temperature and power delivery profiles along the collector row at noon for both days are shown in Fig. 3(a). The three sections can be clearly distinguished. Although the useful energy along the collector in a summer day is substantially larger than in a winter day, fluid temperature along the collector is practically the same for both days. The control system maintains the fluid temperature profile almost constant changing the feed-water flow and the water injection flow. Discontinuity observed near $900 \mathrm{~m}$ is due to water injection. The steam temperature decreases once saturated liquid is injected, with that, absorber temperatures and thermal losses also reduces.

The thermal power can be calculated by integration of the useful energy density curve. On January $29^{\text {th }}$, at noon, it results $1.4 \mathrm{MW}$.

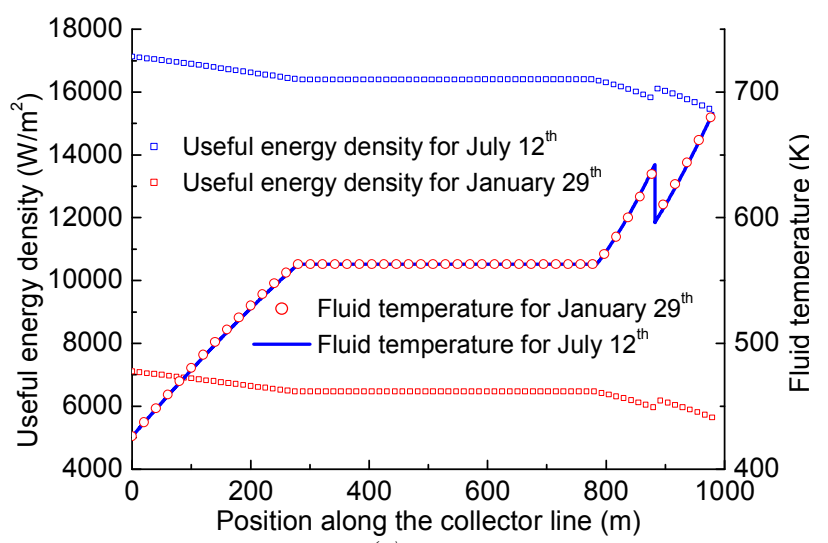

(a)

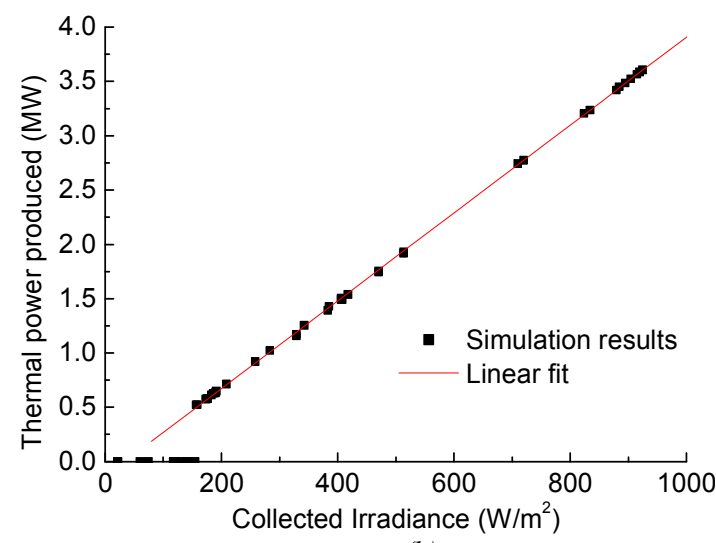

(b)

Figure 3 - (a) The fluid temperature and power delivery profiles along the rowof collectors and (b) thermal output power versus collected irradiance.

Fig. 3(b) shows the thermal output power versus collected irradiance, which means the direct solar irradiance taken into account the effect of the incident angle modifier and row shading. A linear behavior of the thermal power can be observed for collected irradiances greater than a critical value $\left(170 \mathrm{~W} / \mathrm{m}^{2}\right)$. This critical value must increase when all losses that were not considered in this initial implementation are included. For collected irradiances greater than the critical value, a linear fit $(Y=$ $0.004 * X-0.1372$ ) can be used to obtain the thermal output power from irradiances data for a specified local. This linear function is valid only for a collector row with the configuration and parameters simulated, and it will also change when all losses are considered.

\section{CONCLUSIONS}

An analytical solution was derived that allows calculating all the variables along the absorber, involved in DSG process in parabolic through collectors: external and internal absorber temperature, fluid flow and temperature, vapor title, and useful energy. Simulations using an initial implementation of the model indicate good agreement with previous works. However, it is yet necessary to compare the model results with experimental data. Since the model requires only input parameters typically known in any design study, it is expected to obtain, at the end of its implementation, a simple computational tool to simulate DSG systems. A linear relationship between thermal output and collected irradiance has been obtained. Using the utilizability method, this result enables to make long term predictions about the system's performance.

\section{ACKNOWLEDGEMENTS}

The authors would like to thank the Brazilian National Counsel of Technological and Scientific Development (CNPq) for the financial support.

\section{REFERENCES}

Eck M. et al.(2008) Direct steam generation in parabolic troughs at 500 _ - A German-Spanish project targeted on component development and system design. In: Proceedings of 14th International SolarPACES Symposium on Solar Thermal Concentrating Technologies, Las Vegas, USA.

Fernández-García A., Zarza E., Valenzuela L., Pérez M. (2010). Parabolic-trough solar collectors and their applications. Renewable and Sustainable Energy Reviews 14, 1695-1721.

Fraidenraich N., Gordon J. M., Lima R. C. F. (1997). Improved Solutions for Temperature and Thermal Power Delivery Profiles in Linear Solar Collectors. Solar Energy 61, 3, 141-145.

Goebel, O. (1999). Thermohydraulics of direct steam generation. Journal de Physique IV, vol 9, PR3: 9th SolarPACES International Symposium on Solar Thermal Concentrating Technologies, France, 22-26 June 1998.

Protermosolar. (2011). Mapa interactivo de las Centrales Solares Termoélectricas en España, http://www.protermosolar.com/boletines/23/Mapa.pdf. 
Zarza E., Valenzuela L., León J., Hennecke K., Eck M., Dieter Weyers H., Eickhoff M. (2004). Direct Steam Generation in Parabolic Trough: Final Results and Conclusions of the DISS Project. Energy 29, 635-644.

Zarza E., Rojas E. M., González L., Caballero J. M., Rueda F.. (2006). INDITEP: The first pre-commercial DSG Solar power plant. Solar Energy 80, 1270-1276.

Zarza E., López C., Cámara A., Martinez A., Burgaleta J. I., Martín J. C., Fresneda A. (2008). Almería GDV: the first solar power plant with direct stem generation. Proceedings of 14th International SolarPACES Symposium on Solar Thermal Concentrating Technologies, Las Vegas, USA.

\section{RESUMEN}

Generación directa de vapor (GDV) en los tubos absorbedores de colectores solares cilindro parabólicos es un procedimiento promisorio ya que utiliza agua como fluido térmico en lugar de aceite (utilizado en los procedimientos convencionales). Permite temperaturas y por tanto eficiencias más elevadas del ciclo Rankine, reduciendo el costo del sistema. Este trabajo presenta un modelo analítico del proceso GDV en colectores solares cilindro-parabólicos. La columna de colectores fue dividida en tres secciones y se obtuvo un sistema de ecuaciones diferenciales para cada una de ellas. El modelo fue implementado y las simulaciones se realizaron con una configuración y parámetros similares a los trabajos publicados en la literatura técnica. Los resultados muestran un buen acuerdo con ellos y permiten la obtención de muchos parámetros importantes del proceso GDV a lo largo de la columna de colectores: temperatura interna y externa del tubo absorbedor, caudal y temperatura del fluido térmico, título de vapor y energía útil. Se ha obtenido una relación lineal entre la energía útil y la irradiación solar colectada. Por medio del método de utilizabilidad, este resultado permite hacer predicciones a largo plazo sobre el rendimiento del sistema.

Palabras clave: GDV, modelo matemático, cilindro parabólico, energía solar. 